\title{
Development of Transdermal Delivery System of Dexamethasone, Palonosetron and Aprepitant for Combination Antiemetic Therapy
}

\author{
Noor Kamil*, Anroop B Nair, Mahesh Attimarad \\ Department of Pharmaceutical Sciences, College of Clinical Pharmacy, King Faisal University, Al-Ahsa, KSA
}

\begin{abstract}
Purpose: The objective of this study was to assess the possible transdermal delivery for combination antiemetic therapy of dexamethasone, palonosetron and aprepitant, commonly prescribed in chemotherapy induced nausea and vomiting. Methods: Pluronic lecithin organogel formulation was optimized to incorporate all the three drugs. The influence of formulation parameters like drug concentration (1-5\% w/w) and permeation enhancers (oleic acid, n-methyl-2-pyrrolidone, propylene glycol and polyethylene glycol 400 ) on the transdermal delivery of selected antiemetic agents were evaluated ex vivo. Results: Drug release profiles of dexamethasone, palonosetron and aprepitant from the gels were distinct and biphasic in nature. Higher permeability coefficient was observed in palonosetron, average in dexamethasone and was least in aprepitant. Proportional enhancement in the transdermal fluxes of all the three actives were observed with increase in drug concentrations studied. The highest drug concentrations were further treated with different chemical skin enhancers, which improved (1.2-3.3 folds) the permeability coefficient of actives, but not to the same extent. Greater flux values were observed with oleic acid (for dexamethasone) and propylene glycol (for palonosetron and aprepitant). Concomitant transdermal delivery reduced the flux values $(P<0.001)$ of dexamethasone $\left(9.82 \pm 1.39 \mu \mathrm{g} / \mathrm{cm}^{2} / \mathrm{h}\right)$, palonosetron $\left(21.36 \pm 1.95 \mu \mathrm{g} / \mathrm{cm}^{2} / \mathrm{h}\right)$ and aprepitant $(5.04 \pm$ $0.62 \mu \mathrm{g} / \mathrm{cm}^{2} / \mathrm{h}$ ), compared to their corresponding values when evaluated individually. Conclusion: This study conclude that the optimized pluronic lecithin organogel could be utilized for the simultaneous transdermal delivery of dexamethasone, palonosetron and aprepitant, which need to be proved further in vivo.
\end{abstract}

Keywords: Transdermal; dexamethasone; palonosetron; aprepitant; organogel; enhancer

\section{INTRODUCTION}

Cancer is one of the most life threatening and devastating diseases known to affect human. Chemotherapy is the foundation of treatment for most cancer to improve patient outcomes in oncology. In general, the cancer chemotherapy treatment protocols are cytotoxic in nature and causes unbearable and distressing adverse effects. Among these, chemotherapy induced nausea and vomiting (CINV) is the most severe and most distressing toxicity affecting patient's quality of life. ${ }^{1}$ One of the major causes of nausea and vomiting in the cancer patients is drug administration including cytotoxic and opioid analgesics. Three antiemetic treatment guidelines have been derived from large multicenter well controlled clinical trials, however, the basic principles and key issues remain same. One the other hand, management of CINV is a huge burden on medical care and require the use of rescue medication and emergency admission. CINV is divided
Submission Date: 02-03-2016 Revision Date : :15-04-2016 Accepted Date : :04-05-2016

DOI: 10.5530/ijper.50.3.22

Correspondence: Noor Kamil,

Assistant Professor, Department of Pharmaceutical Sciences College of Clinical Pharmacy, King Faisal University, P.O. 400, Al-Ahsa-31982, Kingdom of Saudi Arabia. Email:nkamil@kfu.edu.sa Tel:966-534-541-157

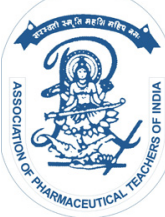

www.ijper.org 
into three major groups; acute emesis, begins within 1-2 $\mathrm{h}$, delayed emesis occurs $24 \mathrm{~h}$ after chemotherapy and anticipatory emesis occur prior to chemotherapy as a condition response due to previous chemotherapy experience. $^{2}$ Uncontrolled CINV can cause serious medical complications, electrolyte imbalances, nutritional deficiency, dehydration and physical and mental disturbances. It can also leads to poor compliance and patient refusal to the possible beneficial cancer chemotherapy.

Discovery of highly safe and selective serotonin receptor antagonist of type 3 was a breakthrough in palliative care of CINV. Antiemetic activity of these drugs are mediated mainly by blocking peripheral serotonin-3 receptors on extrinsic intestinal vagal, spinal afferent nerves and in part antagonizing vomiting center and chemoreceptor trigger zone in central nervous system. Currently various first generation (e.g. granisetron, dolasetron, ondansetron, tropisetron) and one new generation drug (palonosetron) are available for the management of CINV. Newer generation drug palonosetron (Figure 1a) has 30 to 100 times higher affinity towards $5 \mathrm{HT}_{3}$ receptors. ${ }^{3} \mathrm{In}$ addition, neurokinin 1 (NK1) receptor antagonists are also found to be very effective in antiemetic therapy. Its major pharmacological effect is mediated via central block in the area postrema. An oral dosage form of aprepitant (Figure1b) is found to be highly selective NK-1 receptor antagonist after crossing the blood brain barrier. ${ }^{4}$ Another very important and effective addition in antiemetic combination are corticosteroids (dexamethasone and methylprednisolone). Dexamethasone (Figure 1c), a corticosteroid is most widely studied and is effective in both acute and delayed emesis. ${ }^{5}$ The therapeutic efficiency increased significantly when aprepitant is combined with 5HT-3 receptor antagonists and corticosteroids for the prevention of acute to delayed CINV after highly emetogenic chemotherapy. Similarly, combination of aprepitant, a 5-HT-3 receptor antagonist, and dexamethasone prevents acute emesis in $80-90 \%$ of patients compared with less than $70 \%$ treated without aprepitant. ${ }^{6}$ Delayed emesis prevented in $70 \%$ of patients receiving combined therapy versus $30-50 \%$ without aprepitant. In this context, current guidelines for CINV suggests multidrug approach because no single therapeutic agent proved to be effective for prevention and control of CINV. Thus the recent management of CINV comprised of three very effective drugs such as dexamethasone, palonosetron and aprepitant. ${ }^{7}$ This combination is administered by intra-venous route, which is invasive as well as possess less patient compliance. Thus an alternative route for combination antiemetic therapy in CINV could be more advantageous.
Transdermal drug delivery technology is suitable for a wide variety of pharmaceutical application and/or drug compounds due to its high adaptability and versatility. ${ }^{8}$ It involves the application of drug to the skin to obtain the desired therapeutic effect for the treatment of disease far from the site of application. Transdermal drug delivery renders accurate amount of drug from the skin to achieve systemic action. Its non-invasive nature is an additional advantage which provide incessant drug delivery to skin similar to intravenous administration, eliminating the vascular access. ${ }^{9}$ Among the various transdermal delivery systems, topical gel technology has gained the attention of drug delivery scientists due to its superior efficiency, low irritation and higher patient satisfaction. Additionally, this system offers a tailored pharmacokinetic profiles in respect of specified nature of active pharmaceutical compound. Moreover, the gel system has the capability to deliver the drug over a very long period of time from 12 to $24 \mathrm{~h}$ continuously make it suitable for once daily application. ${ }^{10}$ The objective of this study was to investigate the feasibility of developing a transdermal delivery system for combination antiemetic therapy of dexamethasone, palonosetron and aprepitant and its evaluation ex vivo.

\section{MATERIAL AND METHODS}

\section{Materials}

Palonosetron hydrochloride, aprepitant, dexamethasone, polyethylene glycol 400, oleic acid, N-methyl-2-pyrrolidone, tetraglycol, propylene glycol, lecithin and isopropyl palmitate were commercially purchased. Other reagents and chemicals used were of the highest reagent grade available and obtained from commercial suppliers.

\section{Analytical methods}

Simultaneous estimation of dexamethasone, palonosetron and aprepitant was carried out using reverse phase high performance liquid chromatography (HPLC) method ${ }^{11}$ with diode array detector (Agilent, 1200 series, Germany). The chromatographic separation was achieved on zorbax C18 column (150 mm X $4.6 \mathrm{~mm}$ i.d, $5 \mu \mathrm{m}$ ) with mobile phase consisting of acetonitrile and $0.1 \%$ formic acid $(30: 70 \mathrm{v} / \mathrm{v})$. The mobile phase was pumped at the rate of $1.2 \mathrm{~mL} / \mathrm{min}$ and $20 \mu \mathrm{L}$ sample was injected. The column oven temperature was maintained at $25^{\circ} \mathrm{C}$. Detector was set at $208 \mathrm{~nm}$ for dexamethasone and aprepitant and at $240 \mathrm{~nm}$ for palonosetron detection. The retention time $\left(t_{R}\right)$ of the palonosetron, dexamethasone and aprepitant were found to $6.14,11.25$ and $15.32 \mathrm{~min}$ respectively. The calibration curves (peak area vs concentration) were constructed in the range of $0.5-8 \mu \mathrm{g} / \mathrm{mL}$, 
$0.2-5 \mu \mathrm{g} / \mathrm{mL}$ and $0.1-12 \mu \mathrm{g} / \mathrm{mL}$ for dexamethasone, aprepitant and palonosetron, respectively with excellent correlation $\left(r^{2}>0.998\right)$ for all the three analytes. The concentration of analytes in the samples of release study and permeation study was determined with respective regression equations.

\section{Formulation of pluronic lecithin organogels}

The gel contain palonosetron hydrochloride, aprepitant and dexamethasone was formulated by preparing organic and aqueous phases separately. Briefly, the organic phase was prepared by weighing required amount of lecithin and isopropyl palmitate $(1: 1)$ in a glass vial. To this required amount of sorbic acid $(0.2 \% \mathrm{w} / \mathrm{w})$ was added, mixed and the dispersion was kept overnight (12h) for complete dissolution to obtain a homogenous clear solution. Similarly, the aqueous phase was prepared by cold process. ${ }^{12}$ The required amount of poloxamer $407(20-30 \% \mathrm{w} / \mathrm{v})$ and potassium sorbate $(0.2 \% \mathrm{w} / \mathrm{w})$ were weighed and added slowly to the cold water with continuous stirring at lower temperature $\left(4-5{ }^{\circ} \mathrm{C}\right)$ until the polymer was uniformly dispersed. The dispersion was refrigerated $\left(4-5^{\circ} \mathrm{C}\right)$ overnight $(12 \mathrm{~h})$ to obtain a homogenous clear solution. Drugs were dissolved in suitable solvents [palonosetron hydrochloride in water, dexamethsone in mixture of tween 80 and ethanol (95\%) (1:1) and aprepitant in mixture of tetraglycol, tween 80 and ethanol (95\%) (1:1:4)] with continuous stirring and added to the organic phase and mixed using magnetic stirrer to obtain a clear solution. After that the cold aqueous phase (4 parts) was added slowly to the organic phase (1 part) under continuous stirring at low temperature $\left(4-5^{\circ} \mathrm{C}\right)$ using homogenizer to obtain gel.

Influence of drug concentration on the transdermal flux was evaluated by dissolving different concentration of drugs in suitable solvents and added to the organic phase. In addition, the effect of different chemical skin permeation enhancers on the transdermal delivery of palonosetron, aprepitant and dexamethasone was evaluated by incorporating adequate amount of respective agents in organic or aqueous phases, based on their solubility. The concentration of enhancers used was $5 \% \mathrm{w} / \mathrm{v}$.

\section{Amount of drug in gel formulations}

The quantification of palonosetron, aprepitant and dexamethasone in the prepared gel formulations was determined by HPLC. Briefly, $100 \mathrm{mg}$ of gel was precisely weighed and transferred to a polypropylene centrifuge tube and added $25 \mathrm{~mL}$ of mobile phase. The solution was vortexed for $10 \mathrm{~min}$, centrifuged $(10,000 \mathrm{rpm}$; R-83; Remi, Mumbai, India), the supernatant (1 mL) was filtered ( $0.22 \mu \mathrm{m}$, Millex syringe filter unit), appropriately diluted with mobile phase and analyzed by the HPLC.

\section{Drug release studies}

Release of the drug from fabricated gel was evaluated using the Franz diffusion cell (Logan Instruments Ltd., Somerset, NJ). A cellulose dialysis membrane $(2.4 \mathrm{~nm}$ porosity) was soaked in water for $24 \mathrm{~h}$ and was clamped between two chambers of the Franz cell. The effective surface area for all the experiments was $0.64 \mathrm{~cm}^{2}$. The receiver chamber was filled with phosphate buffered saline (PBS; pH 7.4) with $10 \%$ of tween 80 as surfactant to establish sink condition. Further, $\sim 1 \mathrm{~mL}$ of buffer was placed in the donor chamber and the membrane was equilibrated for $1 \mathrm{~h}$ by continuously stirring the receiver chamber at $600 \mathrm{rpm}$ at $37 \pm 0.5^{\circ} \mathrm{C}$. One hour later, donor and receptor fluid were removed and gel formulation $(500 \mathrm{mg}$ ) was placed on the membrane and occluded with parafilm to prevent evaporation of solvent. The receptor compartment was filled with fresh buffer solution $(5 \mathrm{~mL})$. Release experiment was carried for a span of $12 \mathrm{~h}$. Aliquots of dissolution medium were withdrawn at assigned intervals and substituted with fresh media to compensate the loss of sample withdrawn. Later on, all samples were filtered $(0.2 \mu \mathrm{m}, 25 \mathrm{~mm}$; Millex syringe filter) and analyzed by the HPLC.

\section{Skin preparation}

The skin samples were prepared from Wistar rats after a cautious epilation of skin and subsequent removal of subdermal tissue while all other layers (stratum corneum, epidermis, and dermis) remain intact. The prepared samples were washed carefully with isotonic saline solution and preserved at $-20{ }^{\circ} \mathrm{C}$ in aluminium foil. Prior to the permeation studies skin membrane was thawed and membrane resistance was measured to ensure the resistance of $>20 \mathrm{k} \Omega \cdot \mathrm{cm}^{2}$ which was proved suitable in our earlier studies. ${ }^{13}$

\section{Ex vivo permeation studies}

Permeation studies were performed in a Franz diffusion cell (Logan Instruments Ltd., Somerset, NJ) using the rat skin. ${ }^{14}$ Membrane was placed between two chambers in such a way that dorsal side of skin was exposed to receptor medium [phosphate buffered saline (PBS) solution of $\mathrm{pH} 7.4$ with $10 \%$ tween 80]. The skin surface area available for all experiments was $0.64 \mathrm{~cm}^{2}$. Skin membrane of full thickness was equilibrated in PBS for $1 \mathrm{~h}$ with donor $(1 \mathrm{~mL})$ and receptor $(5 \mathrm{~mL})$. Then both liquids (receptor and donor) were removed and gel $(500 \mathrm{mg})$ was applied uniformly on the skin surface. Receptor chamber $(5 \mathrm{~mL})$ was replenished with fresh 
PBS solution and constantly stirred at $600 \mathrm{rpm}$ at $37 \pm$ $0.5^{\circ} \mathrm{C}$. Experiment for permeation was carried out for $24 \mathrm{~h}$ and an aliquot of the receiver fluid was analyzed at planned intervals of time.

\section{Drug concentration effect on permeation}

The effect of drug (palonosetron, aprepitant and dexamethasone) concentrations (0.5, 1 and $2.5 \% \mathrm{w} / \mathrm{w})$ on their transdermal permeation was carried out similarly as described in ex vivo permeation studies before. Gel formulation $(500 \mathrm{mg})$ was placed on the donor compartment. The quantity of drug permeated at various time intervals was measured by the HPLC.

\section{Effect of enhancers on permeation}

The effect of different chemical skin permeation enhancers (oleic acid, n-methyl-2-pyrrolidone, propylene glycol and polyethylene glycol 400) on the transport of palonosetron, aprepitant and dexamethasone was carried out similarly as described before. The amount of drug permeated at different time intervals was measured by the HPLC.

\section{Skin irritation study}

Skin irritation study was examined for the prepared gel and standard skin irritant (2.5\% sodium dodecyl sulfate). Prepared gel was applied on the left and right dorsal surface of rat skin and graded for erythema and edema for one day. The test score was assigned according to draize dermal scoring criteria. ${ }^{15}$

\section{Stability studies}

The gel formulation was sealed in a glass vials and stored for a period of 2 months at $25 \pm 1{ }^{\circ} \mathrm{C}$ and $75 \pm 5 \%$ relative humidity to determine the physical and chemical stability. ${ }^{16}$ The formulation was evaluated for consistency and drug content.

\section{Data analysis}

A graph of drug permeated per unit area of skin versus time was plotted and flux has been calculated from the linear portion of the plotted area. Permeability coefficient $(\mathrm{Kp})$ was determined by dividing flux with donor drug concentration. ${ }^{17}$ Enhancement was measured as the amount of drug permeated $\left(\mu \mathrm{g} / \mathrm{cm}^{2}\right)$ in respective treatment to its control. Level of significant between the two groups were calculated by Graphpad prims version 5, graphpad software, Inc., CA, USA. Six trials \pm standard deviation (SD) were recorded in data. P value of $<0.05$ was considered as significant.

\section{RESULTS AND DISCUSSION}

The physicochemical properties and biopharmaceutics related properties of dexamethasone, palonosetron and aprepitant are summarized in Table 1. Considering these properties a preliminary study was initiated to assess the feasibility of fabricating transdermal patch of these drugs using various pressure sensitive adhesives (Duro-Taks). However, solubility of these drugs in different adhesives were found to be relatively low (data not shown). Thus it was thought worth to develop a gel formulation as an alternative. Indeed, the transdermal delivery of actives from gel formulations has received much attention owing to its unique advantages. In this perspective, pluronic lecithin organogels could be the most feasible option to incorporate dexamethasone, palonosetron and aprepitant, in view of their solubility (Table 1). Literature suggest that pluronic lecithin organogels are extensively used in transdermal formulations as it can incorporate drug molecules with distinct solubility, no skin irritation, potential to disturb the lipid bilayer layer in the stratum corneum, provides rapid permeation etc. ${ }^{18}$

The gel composition used in this study was optimized by varying the ratio of lecithin, isopropyl palmitate and poloxamer. Additionally, poloxamer used in the formulation is a copolymer which also own certain surfactant property and is likely to enhance the percutaneous absorption of actives. ${ }^{19}$ Further, drug solutions were prepared by permutation combinations of surfactant (Tween 80), primary co-solvent (ethanol) and secondary co-solvent (tetraglycol). The solubility of all three drugs were tested individually in the gel formulation (data not included), and the concentrations used for the studies were well below their saturation level and was calculated based on their clinical dose using an equation described in literature. ${ }^{20}$

Drug release studies were carried out for a period of $8 \mathrm{~h}$ using optimized formulation and the percentage drug release was depicted in Figure 2. The duration of the study was fixed for $8 \mathrm{~h}$ as the drug release was complete during this period. It is apparent from Figure 2 that release profiles of dexamethasone, palonosetron and aprepitant were slightly different. The drug release behavior were applied into mathematical models ${ }^{21}$ to determine the drug release behavior, and the ideal kinetic models were found different for dexamethasone, palonosetron and aprepitant. The rate of release was relatively high with palonosetron which was followed by dexamethasone and then aprepitant. It is also evident that the release was rapid in the first one hour (palonosetron $\sim 75 \%$, dexamethasone $\sim 50 \%$ and aprepitant $\sim 35 \%$ ), 


\begin{tabular}{|c|c|c|c|c|c|c|c|c|}
\hline Drug & $\begin{array}{c}\mathrm{MW}(\mathrm{g} / \\
\mathrm{mol})\end{array}$ & $\begin{array}{l}\text { Melting } \\
\text { Point }\left({ }^{\circ} \mathrm{C}\right)\end{array}$ & $\begin{array}{c}\text { Aqueous } \\
\text { Solubility } \\
(\mu \mathrm{g} / \mathrm{mL})\end{array}$ & $\log P$ & Pka & BCS class & $\begin{array}{l}\text { Half Life } \\
\text { (h) }\end{array}$ & $\begin{array}{l}\text { Oral dose } \\
\quad(\mathrm{mg})\end{array}$ \\
\hline Dexamethasone & 392.46 & 262 & $\sim 89$ & 1.83 & 12.42 & III & $\sim 3 \mathrm{~h}$ & 12 \\
\hline Palonosetron $\mathrm{HCl}$ & 332.86 & 240 & $\sim 464$ & 2.7 & 7.97 & III & $\sim 40 \mathrm{~h}$ & 0.5 \\
\hline Aprepitant & 534.42 & 245 & $\sim 3-7$ & 4.5 & 9.7 & IV & $\sim 10 \mathrm{~h}$ & 125 \\
\hline
\end{tabular}

suggesting a biphasic release pattern (Figure 2). This rapid release observed from the prepared gel substantiated our choice of formulation composition for these drugs to provide effective delivery. Moreover, this prompt release could be helpful in providing higher drug concentration in the skin surface which in turn can leads to rapid transport of drug molecules. Followed by the rapid release there was a slow phase even though the drug release was complete in $4 \mathrm{~h}$ and $6 \mathrm{~h}$ for palonosetron and dexamethasone, respectively. However in case of aprepitant, percentage release appeared to be steady and controlled after $2 \mathrm{~h}$ and continued until $8 \mathrm{~h}$. The observed difference in percentage release between drug formulations could be associated to their aqueous solubility and partition coefficient. The complete release of drugs seen in the current study (varies between 4-8 h) could be beneficial to prolong the transdermal therapy, provided the gel is retained on the skin surface for such a long application period. This extended period of drug release (up to $8 \mathrm{~h}$ ) from the prepared gel formulation will make one to presume that there could be formation of microemulsion inside the gel and its possibility is not ruled out, but need to be examined. This is because the current formulation composition have the all ingredients such as oil, water surfactant, required for the formulation of microemulsions. ${ }^{22}$ In addition, the presence of microemulsion could be advantageous as they reported to enhance the transdermal permeation of several drug molecules. ${ }^{23}$

Ex vivo permeation experiments are considered as a pilot study to the in vivo performance of therapeutic agents. The transport of actives through any physiological membranes is affected by its thickness and content. ${ }^{24}$ Physicochemical properties in general and lipophilicity in particular plays an important role in the percutaneous absorption of therapeutic actives. Thus the rule of thumb in transdermal delivery is that the flux is proportionate to partition coefficient and diffusivity. ${ }^{25}$ The physicochemical and biopharmaceutical related properties of dexamethasone summarized in Table 1 suggests low molecular weight, good partition coefficient, low melting point, short half-life and small dose, that support its transdermal application. Thus the preliminary study was initiated to assess the effect of dexamethasone concentrations $(0.5-1.5 \% \mathrm{w} / \mathrm{w} /)$ on the permeability across the full thickness rat skin and depicted in Figure 3. It can be seen that the permeation profile seems to be typical transdermal type, irrespective of concentration studied. As expected, increase in drug concentration, proportionally enhance the permeation of dexamethasone, as observed with the flux values in Table 2. Moreover, detectable amount of dexamethasone was found in the received in the first hour of study, means no lag time in the current study. However, the permeability coefficient observed was relatively low, substantiating the BCS classification as Class III. On the other hand, the highest dexamethasone concentration studied $(1.5 \% \mathrm{w} / \mathrm{w} /)$ was not the maximum concentration we could incorporate in the optimized gel formulation. In the current experimental condition, it is possible to incorporate the concentration of dexamethasone till $3 \% \mathrm{w} / \mathrm{w}$ and the permeation studies also showed corresponding enhancement in flux (data not shown). The dexamethasone concentrations $(0.5-1.5 \% \mathrm{w} / \mathrm{w} /)$ represented in Figure 3 is for comparison purpose with other drugs.

Palonosetron hydrochloride is also under BCS class III category with good water solubility, low molecular weight/ melting point, good $\log \mathrm{P}$ and very low dose (Table 1). Figure 4 compares the ex vivo permeation profiles of palonosetron hydrochloride at three different concentrations $(0.5-1.5 \% \mathrm{w} / \mathrm{w} /)$. It is apparent from Figure 4 that the amount of drug permeation was relatively high and rapid than dexamethasone. The cumulative amount of drug permeated at the end of $24 \mathrm{~h}$ was found to be $156.76 \pm 42.77 \mu \mathrm{g} / \mathrm{cm}^{2}, 274.78 \pm$ $54.74 \mu \mathrm{g} / \mathrm{cm}^{2}$ and $368.43 \pm 50.24 \mu \mathrm{g} / \mathrm{cm}^{2}$, when the donor concentration was $0.5 \%, 1 \%$ and $2 \%(\mathrm{w} / \mathrm{w})$, respectively. The flux values and permeability coefficient was almost two fold higher than the dexamethasone values (Table 2). Drug concentration was detected in the receptor compartment in the first hour itself and there was no lag time.

Properties of aprepitant is different when compared to dexamethasone and palonosetron (Table 1). The molecular 


\begin{tabular}{|c|c|c|c|c|}
\hline $\begin{array}{l}\text { Drug concentration } \\
\qquad(\% \mathrm{w} / \mathrm{w})\end{array}$ & $\begin{array}{l}\text { Enhancer } \\
(5 \% \mathrm{w} / \mathrm{w})\end{array}$ & $\begin{array}{c}\text { Flux } \\
\left(\mu \mathrm{g} / \mathrm{cm}^{2} / \mathrm{h}\right)\end{array}$ & $\begin{array}{c}\text { Permeability } \\
\text { coefficient } \\
\left(\mathrm{Kp} \times 10^{-4}\right)\end{array}$ & Enhancement \\
\hline Dexamethasone $(0.5 \%)$ & - & $3.45 \pm 0.69$ & $6.89 \pm 0.82$ & - \\
\hline Dexamethasone (1\%) & - & $6.28 \pm 0.95$ & $6.28 \pm 0.69$ & - \\
\hline Dexamethasone (1.5\%) & - & $8.99 \pm 1.21$ & $5.99 \pm 0.84$ & 1 \\
\hline Dexamethasone (1.5\%) & Oleic acid & $18.82 \pm 2.65$ & $12.55 \pm 1.06$ & 2.09 \\
\hline Dexamethasone (1.5\%) & N-methyl-2-pyrrolidone & $12.86 \pm 2.08$ & $8.57 \pm 0.91$ & 1.43 \\
\hline Dexamethasone (1.5\%) & Propylene glycol & $10.66 \pm 1.37$ & $7.11 \pm 0.83$ & 1.19 \\
\hline Dexamethasone (1.5\%) & Polyethylene glycol 400 & $10.33 \pm 1.51$ & $6.88 \pm 0.76$ & 1.15 \\
\hline Palonosetron $(0.5 \%)$ & - & $6.53 \pm 0.82$ & $13.06 \pm 0.80$ & - \\
\hline Palonosetron (1\%) & - & $11.45 \pm 1.72$ & $11.45 \pm 0.97$ & - \\
\hline Palonosetron (1.5\%) & - & $15.35 \pm 1.54$ & $10.23 \pm 0.54$ & 1 \\
\hline Palonosetron (1.5\%) & Propylene glycol & $35.52 \pm 3.96$ & $23.68 \pm 1.65$ & 2.31 \\
\hline Palonosetron (1.5\%) & Polyethylene glycol 400 & $29.61 \pm 2.27$ & $19.74 \pm 1.34$ & 1.93 \\
\hline Palonosetron (1.5\%) & Oleic acid & $23.00 \pm 1.35$ & $15.33 \pm 0.81$ & 1.50 \\
\hline Palonosetron (1.5\%) & $\mathrm{N}$-methyl-2-pyrrolidone & $18.75 \pm 1.81$ & $12.50 \pm 0.64$ & 1.22 \\
\hline Aprepitant $(0.5 \%)$ & - & $1.91 \pm 0.42$ & $3.82 \pm 0.47$ & - \\
\hline Aprepitant (1\%) & - & $3.57 \pm 1.28$ & $3.57 \pm 0.68$ & - \\
\hline Aprepitant (1.5\%) & - & $5.06 \pm 0.77$ & $3.37 \pm 0.52$ & 1 \\
\hline Aprepitant (1.5\%) & Propylene glycol & $16.53 \pm 1.08$ & $11.02 \pm 0.83$ & 3.27 \\
\hline Aprepitant (1.5\%) & N-methyl-2-pyrrolidone & $12.58 \pm 1.16$ & $8.38 \pm 0.75$ & 2.49 \\
\hline Aprepitant (1.5\%) & Polyethylene glycol 400 & $11.03 \pm 0.84$ & $7.35 \pm 0.91$ & 2.18 \\
\hline Aprepitant (1.5\%) & Oleic acid & $7.91 \pm 0.56$ & $5.27 \pm 0.62$ & 1.56 \\
\hline $\begin{array}{c}\text { Dexamethasone }(1.5 \%)+ \\
\text { Palonosetron }(1.5 \%)+ \\
\text { Aprepitant }(1.5 \%)\end{array}$ & $\begin{array}{c}\text { Propylene glycol + } \\
\text { Oleic acid }\end{array}$ & $\begin{array}{c}9.82 \pm 1.39 \\
21.36 \pm 1.95 \\
5.04 \pm 0.62\end{array}$ & $\begin{array}{c}6.55 \pm 0.75 \\
14.24 \pm 1.27 \\
3.36 \pm 0.51\end{array}$ & - \\
\hline
\end{tabular}

weight, $\log \mathrm{P}$ and melting point values of aprepitant in Table 1 is well in the range of transdermal candidates. However, this drug possess very low aqueous solubility and there were several attempts to solubilize it like solid state manipulation and synthesizing prodrug (fosaprepitant), which are limited by stability issues or complexity in synthesis. The highest concentration of aprepitant that could be incorporated in the optimized formulation was $2 \% \mathrm{w} / \mathrm{w}$, although a lower concentration $(1.5 \% \mathrm{w} / \mathrm{w})$ was used in order to prevent any crystal formation. Figure 5 shows the permeation profiles of aprepitant at three different concentrations $(0.5-1.5 \% \mathrm{w} / \mathrm{w})$ and was somewhat different from other two drugs (dexamethasone and palonosetron). The observed permeation profiles suggest that the flux values increased with increase in the drug concentrations (Figure 5). No measureable amount of drug was detected in the receiver at $1 \mathrm{~h}$ with $0.5 \%(\mathrm{w} / \mathrm{w})$, probably there was a lag time when the concentration of donor is low. However at higher concentrations, detectable amount of dexamethasone was permeated in $1 \mathrm{~h}\left(0.48 \pm 0.23 \mu \mathrm{g} / \mathrm{cm}^{2}\right.$ and $1.35 \pm$ $0.28 \mu \mathrm{g} / \mathrm{cm}^{2}$ with $1 \%$ and $2 \% \mathrm{w} / \mathrm{w}$, respectively). Further, it can be also seen that the permeation rate was relatively slow and low until $4 \mathrm{~h}$ and then followed a steady permeation up to the end of study hour $(24 \mathrm{~h})$. However, the flux and permeability coefficient values were lowest among the three drug molecules tested (Table 2), in the current experimental condition. This low permeability coefficient $\left(\mathrm{Kp}=\sim 3.5 \times 10^{-4}\right)$ is probably because of the high molecular weight and required an additional enhancement approach to improve the permeation. In general, the permeation data observed with all the three drugs were in agreement with the drug release studies. Based on the above data, in all the three cases the flux values were maximum when the drug concentration was highest $(1.5 \% \mathrm{w} / \mathrm{w})$ and hence used for further studies. The role of skin permeation enhancers in improving the percutaneous absorption of therapeutic actives is well known. Hence, next phase of study assess the potential of chemical permeation enhancers to improve the flux of all three drugs. Four renowned permeation enhancers such as oleic acid, n-methyl-2-pyrrolidone, propylene glycol and polyethylene glycol 400 were selected based on the literature. ${ }^{23,26}$ The concentration 
of enhancers $(5 \% \mathrm{w} / \mathrm{w})$ was selected based on the literature wherein it was reported that these agents are safe for human use. ${ }^{26}$ Figure 6 compares the permeation profile of dexamethasone in presence of different chemical agents aimed for improving the permeation. It can be seen that the permeation of dexamethasone was significantly $(\mathrm{P}<0.001)$ higher when along chain fatty acid (oleic acid) was incorporated, and the enhancement was $\sim 2$ folds higher than the control (formulation without enhancer). The reason for significant enhancement in dexamethasone diffusivity could be because of oleic acid's potential to disturb the skin lipids and thereby increase the lipid fluidity. ${ }^{27}$ In contrast, other three percutaneous skin enhancers (n-methyl-2-pyrrolidone, propylene glycol and polyethylene glycol 400) could not contribute much to improve the permeation of dexamethasone and their flux values were comparable to the control (Table 2). However, exact cause for the failure of these skin permeation enhancers is unknown.

Figure 7 compares the cumulative amount of palonosetron permeated across the full thickness skin when tested with different chemical enhancers. The drug permeation significantly enhanced with usage of all the enhancers and it decreased as; propylene glycol $>$ polyethylene glycol 400> oleic acid $>$ n-methyl-2-pyrrolidone, compared to control. The highest flux observed with propylene glycol $\left(35.52 \pm 3.96 \mu \mathrm{g} / \mathrm{cm}^{2} / \mathrm{h}\right)$ was $\sim 3.2$ folds higher than the test formulation $\left(15.35 \pm 1.54 \mu \mathrm{g} / \mathrm{cm}^{2} / \mathrm{h}\right)$. The cumulative amount of palonosetron permeated at the end of $24 \mathrm{~h}$ was $852.45 \pm 55.73 \mu \mathrm{g} / \mathrm{cm}^{2}, 710.67 \pm 21.67 \mu \mathrm{g} / \mathrm{cm}^{2}$, $551.94 \pm 50.23 \mu \mathrm{g} / \mathrm{cm}^{2}$ and $449.93 \pm 50.23 \mu \mathrm{g} / \mathrm{cm}^{2}$ when treated with propylene glycol, polyethylene glycol 400, oleic acid and n-methyl-2-pyrrolidone, respectively. The higher permeability coefficient of palonosetron observed $\left(\mathrm{Kp}=\sim 24 \times 10^{-4}\right)$ when treated with propylene glycol is the highest value observed among various treatments assessed under the current experimental conditions. The improvement in flux values by these enhancers could be linked to their diverse mechanisms reported earlier, ${ }^{23,27,28}$ although it was not examined in the current study. Interestingly, propylene glycol is also reported to inhibit the crystal growth of palonosetron and is widely incorporated in pharmaceutical formulations. The permeation profile of aprepitant with different permeation enhancers are depicted in Figure 8. It is obvious from Figure 8 that all the chemical agents examined have enhanced the transdermal flux of aprepitant in the current experimental condition, although not to a same extent. Values in Table 2 indicate the improvement in aprepitant flux values when permeation enhancers are used (compared to control). The enhancement factor in $24 \mathrm{~h}\left(\mathrm{EQ}_{24}\right)$ was assessed by an equation described by Murthy et a ${ }^{29}$ and were $\sim 3.3, \sim 2.5, \sim 2.2$ and 1.6 folds higher with propylene glycol, n-methyl-2-pyrrolidone, polyethylene glycol 400 and oleic acid, respectively. It is also noticed that the enhancement in transdermal flux of aprepitant $(\sim 3.3$ folds) with propylene glycol is probably the highest among any treatment, in the current experimental condition. Further, the permeability coefficient values observed [propylene glycol $\left(\mathrm{Kp}=\sim 11 \times 10^{-4}\right)$, n-methyl-2-pyrrolidone $\left(\mathrm{Kp}=\sim 8.4 \times 10^{-4}\right)$, polyethylene glycol 400 $\left(\mathrm{Kp}=\sim 7.4 \times 10^{-4}\right)$ and oleic acid $\left.\left(\mathrm{Kp}=\sim 5.3 \times 10^{-4}\right)\right]$ also varies between enhancers tested.

Final phase of study investigated the feasibility of simultaneous transdermal delivery of dexamethasone, palonosetron and aprepitant from the optimized pluronic lecithin organogel. All the three drugs were incorporated in the gel at concentration of $1.5 \%(\mathrm{w} / \mathrm{w})$ each. Permeation enhancers which showed superior efficiency such as oleic acid (in case of dexamethasone) and propylene glycol (in case of palonosetron and aprepitant) were selected and incorporated at concentration of $5 \%(\mathrm{w} / \mathrm{w})$. Moreover, the synergetic effect of these enhancers when combined in enhancing the transdermal flux is also reported. ${ }^{23}$ Figure 9 compares the cumulative amount of dexamethasone, palonosetron and aprepitant permeated through the rat skin. As expected, the permeation profiles were distinct for all three drugs, although the trend was comparable to their individual permeation studies. Measurable amount of drug was detected in the receiver fluid in the initial hour of permeation study $\left(1.12 \pm 0.38 \mu \mathrm{g} / \mathrm{cm}^{2}, 5.40 \pm 1.60 \mu \mathrm{g} / \mathrm{cm}^{2}\right.$ and $1.14 \pm 0.39 \mu \mathrm{g} / \mathrm{cm}^{2}$ for dexamethasone, palonosetron and aprepitant, respectively), which shows there is no lag time. Figure 9 demonstrated greater permeation of palonosetron hydrochloride followed by dexamethasone and was least with aprepitant. The difference in mass transport of drug is likely associated to individual molecules intrinsic physicochemical properties. Indeed, the permeation profiles seems to be a typical transdermal type and was steady throughout the study period $(24 \mathrm{~h})$. It should be borne in mind that the profile observed in the ex vivo permeation will not be similar in vivo and is likely to vary as the half-life of these molecules are significantly different. For instance, the half-life of palonosetron is $\sim 40 \mathrm{~h}$, wherein the drug transported through the skin layers and reaches systemic is likely to stay for long period, when compared to dexamethasone (half-life $\sim 3 \mathrm{~h}$ ). On the other hand, the flux of dexamethasone $(9.82 \pm$ $\left.1.39 \mu \mathrm{g} / \mathrm{cm}^{2} / \mathrm{h}\right)$, palonosetron $\left(21.36 \pm 1.95 \mu \mathrm{g} / \mathrm{cm}^{2} / \mathrm{h}\right)$ and aprepitant $\left(5.04 \pm 0.62 \mu \mathrm{g} / \mathrm{cm}^{2} / \mathrm{h}\right)$ in simultaneous delivery were significantly low $(\mathrm{P}<0.001)$ than their corresponding values observed when assessed individually 
(a)<smiles>O=C1c2cccc3c2[C@H](CCC3)CN1[C@H]1CN2CCC1CC2</smiles>

(b)<smiles>C[C@@H](O[C@@H]1OCCN(Cc2nc(=O)[nH][nH]2)[C@H]1c1ccc(F)cc1)c1cc(C(F)(F)F)cc(C(F)(F)F)c1</smiles>

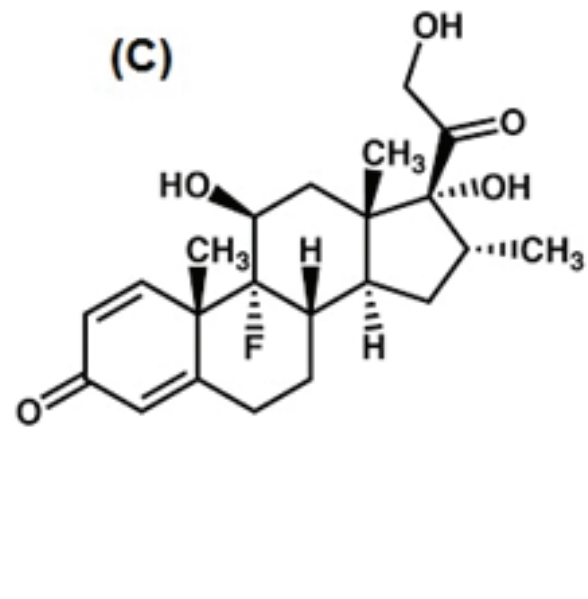

Figure 1: Structure of (a) palonosetron hydrochloride (b) aprepitant and (c) dexamethasone.

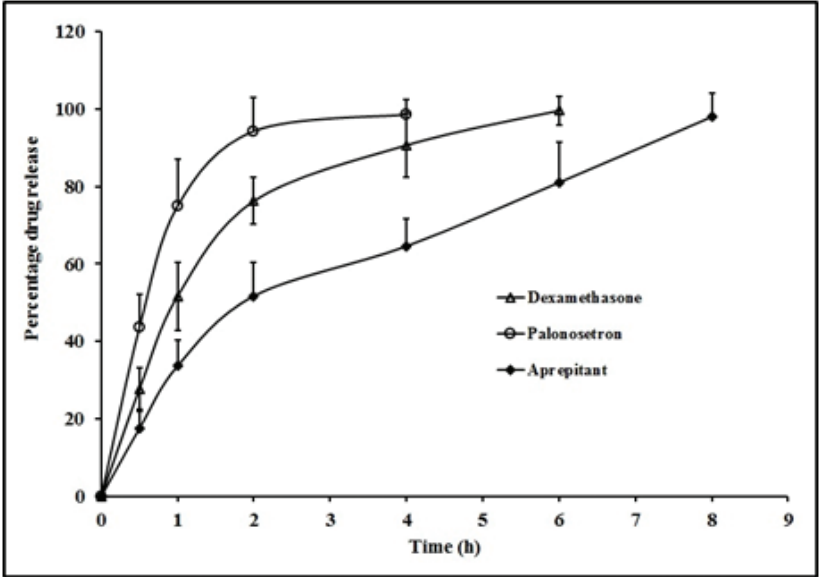

Figure 2: In vitro drug release profiles of dexamethasone, palonosetron hydrochloride and aprepitant from organogels. Each data is an average of six trials.

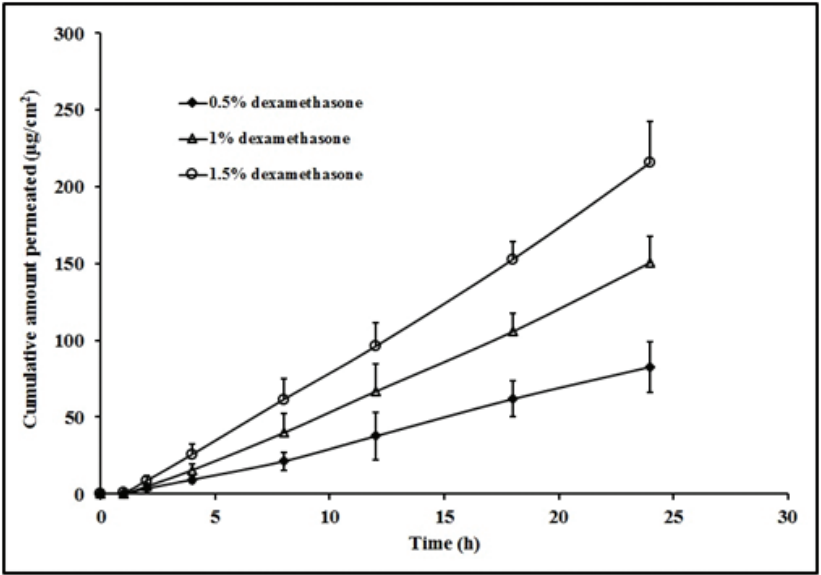

Figure 3: Permeation profiles of dexamethasone at three different drug concentrations from organogels. Each data is an average of six trials.

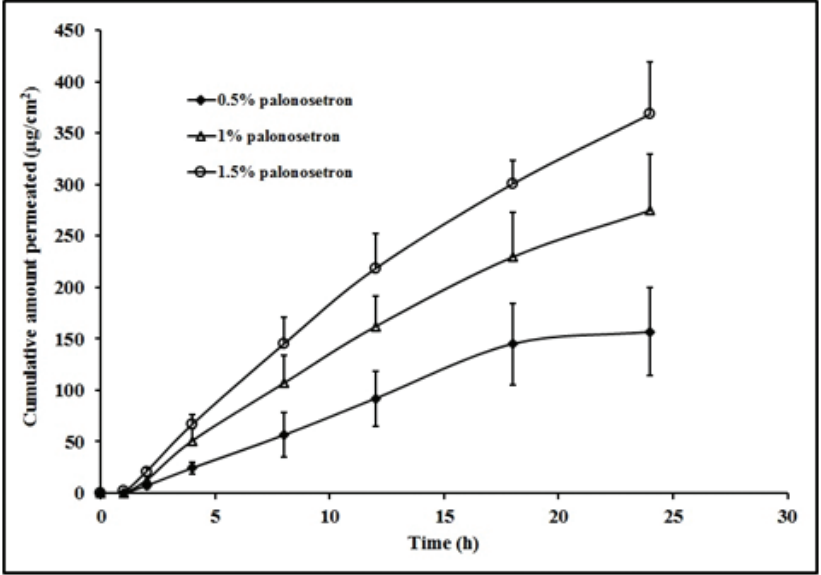

Figure 4: Permeation profiles of palonosetron hydrochloride at three different drug concentrations from organogels. Each data is an average of six trials.

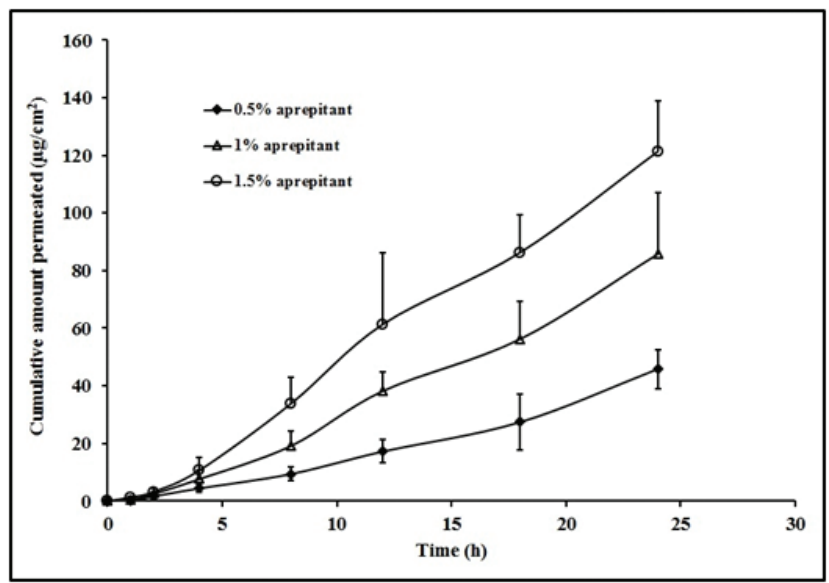

Figure 5: Permeation profiles of aprepitant at three different drug concentrations from organogels. Each data is an average of six trials. 


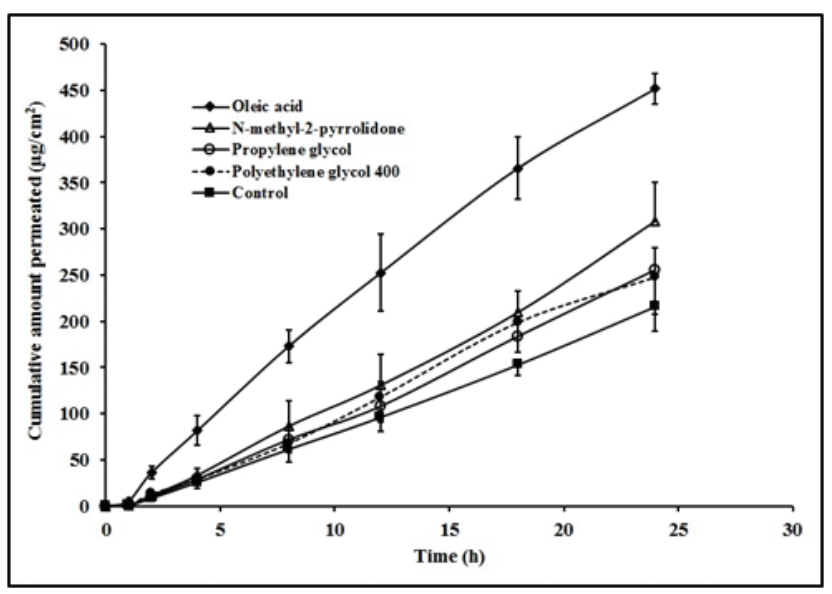

Figure 6: Effect of various chemical skin permeation enhancers on the transdermal delivery of dexamethasone at $1.5 \%(\mathrm{w} / \mathrm{w})$. Each data is an average of six trials.

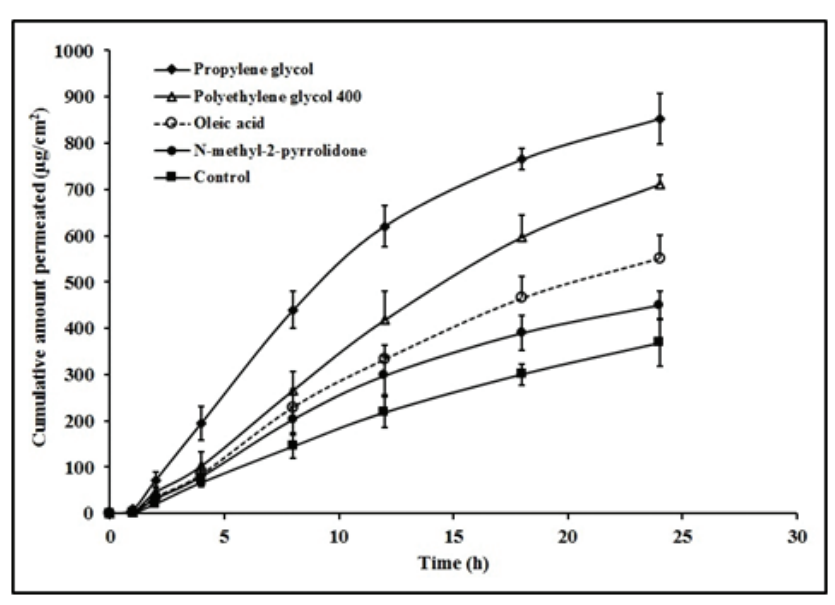

Figure 7: Effect of various chemical skin permeation enhancers on the transdermal delivery of palonosetron hydrochloride at $1.5 \%(w / w)$. Each data is an average of six trials.

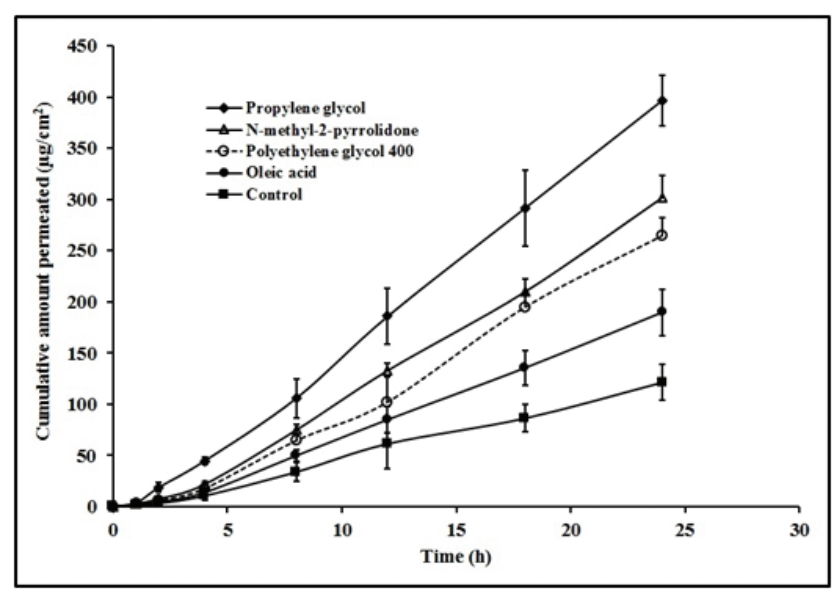

Figure 8: Effect of various chemical skin permeation enhancers on the transdermal delivery of aprepitant at $1.5 \%(w / w)$. Each data is an average of six trials.

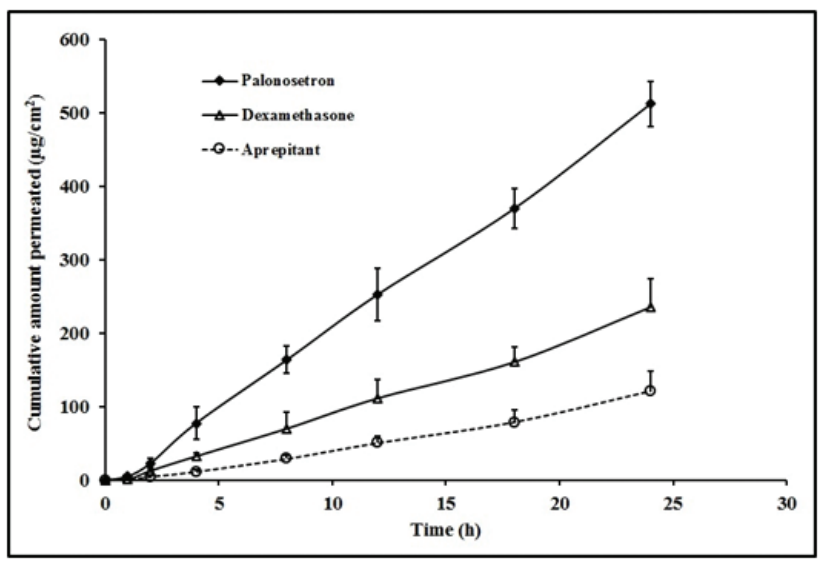

Figure 9: Transdermal permeation of dexamethasone, palonosetron hydrochloride and aprepitant from optimized pluronic lecithin organogel formulation contain $5 \%(w / w)$ of oleic acid and propylene glycol. Each data is an average of six trials.

(Table 2). Moreover, substantial decline in cumulative drug permeation (at $24 \mathrm{~h})$ was noticed $(\sim 50 \%$ for palonosetron, $\sim 60 \%$ for dexamethasone, and $\sim 30 \%$ for aprepitant) than the values observed with when the permeation was carried out alone. The decline in permeation of these three actives from pluronic lecithin organogel could be due to limited active surface area for the effective transport. Thus a greater permeation area or alternative transdermal permeation enhancement approaches such iontophoresis is likely to improve their permeability coefficient, although need to be proved.

Stability studies indicate that the prepared gel formulation did not show any erythema or edema on rat after $24 \mathrm{~h}$ indicates an irritation index of ' 0 ', thus proved to be nonirritant. Stability studies indicate that $>95 \%$ of drugs in the gel formulation when stored at $25 \pm 1^{\circ} \mathrm{C}$ and $75 \pm 5 \%$ for a period of two months.

\section{CONCLUSION}

In the current study the choice of pluronic lecithin organogels was primarily because of the low aqueous solubility of aprepitant and dexamethasone. The effect of formulation parameters such as concentration of drug and permeation enhancers were assessed by in vitro and ex vivo permeation using the rat skin. Concentrations tested with different actives showed significant difference in their permeability coefficients and decreased as; palonosetron $>$ dexamethasone $>$ aprepitant. However, chemical treatment enhanced the transdermal fluxes of all the three actives. Combination of these drugs in single formulation decreased the permeability, compared to their individual delivery. The low permeation potential of these drugs from the gel formulation suggest that the 
individual delivery of these components could be more beneficial than concurrent delivery.

\section{DECLARATION OF INTEREST}

The authors declare that there is no conflict of interests

\section{ACKNOWLEDGMENT}

The authors thank the Deanship of Scientific Research, King Faisal University for funding this research project No. 150099. Also the authors acknowledge Mr. Tameem Al-Yahian, College of Clinical Pharmacy for assistance during this study.

\section{REFERENCES}

1. Rao KV, Faso A. Chemotherapy-induced nausea and vomiting: optimizing prevention and management. Am Health Drug Benefits. 2012; 5(4): 232-40.

2. Hesketh PJ, Bohlke K, Lyman GH, et al. Antiemetics: American society of clinical oncology focused guideline update. J Clin Oncol. 2016; 34(4): 381-6.

3. Fabi A, Malaguti P. An update on palonosetron hydrochloride for the treatment of radio/chemotherapy-induced nausea and vomiting. Expert Opin Pharmacother. 2013; 14(5): 629-41.

4. Diemunsch P, Joshi GP, Brichant JF. Neurokinin-1 receptor antagonists in the prevention of postoperative nausea and vomiting. $\mathrm{Br} \mathrm{J}$ Anaesth. 2009; 103 (1): 7-13.

5. Ioannidis JP, Hesketh PJ, Lau J. Contribution of dexamethasone to control of chemotherapy-induced nausea and vomiting: a meta-analysis of randomized evidence. J Clin Oncol. 2000; 18(19): 3409-22.

6. Roila F, Fatigoni S, Caserta C, et al. Aprepitant versus metoclopramide, both combined with dexamethasone, for the prevention of cisplatin-induced delayed emesis: a randomized, double-blind study. Ann Oncol. 2015; 26(6): 1248-53.

7. Bhandari PR. Recent advances in pharmacotherapy of chemotherapyinduced nausea and vomiting. J Adv Pharm Technol Res. 2012; 3(4): 202-9.

8. Raphael AP, Wright OR, Benson HA, Prow TW. Recent advances in physical delivery enhancement of topical drugs. Curr Pharm Des. 2015; 21(20): 2830-47.

9. Tanner T, Marks R. Delivering drugs by the transdermal route: review and comment. Skin Res Technol. 2008; 14(3): 249-60.

10. Guy RH. Skin-'that unfakeable young surface'. Skin Pharmacol Physiol. 2013; 26(4-6):181-189.

11. Bourdon F, Lecoeur M, Odou P, Vaccher C, Foulon C. Complementarity of UV-PLS and HPLC for the simultaneous evaluation of antiemetic drugs. Talanta 2014; 120: 274-82.
12. Nair AB, Sammeta SM, Vaka SRK, Murthy SN. A study on the effect of inorganic salts in transungual drug delivery of terbinafine. $\mathrm{J}$ Pharm Pharmacol. 2009; 61(4): 431-437.

13. Nair A, Vyas H, Shah J, Kumar A. Effect of permeation enhancers on the iontophoretic transport of metoprolol tartrate and the drug retention in skin. Drug Deliv. 2011; 18(1): 19-25.

14. Nair AB, Kumria R, Al-Dhubiab BE, Attimarad M, Harsha S. Development of transdermal delivery system of vildagliptin and its comparison with oral therapy. Indian J Pharm Educ Res. 2016; 50(1): 130-137.

15. Draize $\mathrm{OH}$, Woodard $\mathrm{G}$, Calvery $\mathrm{HO}$. Methods for the study of irritation and toxicity of substances applied topically to the skin and mucous membranes. J Pharmacol ExpTher. 1944; 82: 377-390.

16. Jacob S, Shirwaikar A, Nair A. Preparation and evaluation of fastdisintegrating effervescent tablets of glibenclamide. Drug Dev Ind Pharm 2009; 35(3): 321-328.

17. Anroop B, Ghosh B, Parcha V, Kumar A, Khanam J. Synthesis and comparative skin permeability of atenolol and propranolol esters. J Drug Del Sci Tech. 2005; 15(2): 187-90.

18. Almeida H, Amaral MH, Lobão P, Lobo JM. Pluronic ${ }^{\circledR}$ F-127 and Pluronic Lecithin Organogel (PLO): main features and their applications in topical and transdermal administration of drugs. J Pharm Pharm Sci. 2012; 15(4):592-605.

19. Dumortier G, Grossiord JL, Agnely F, Chaumeil JC. A review of poloxamer 407 pharmaceutical and pharmacological characteristics. Pharm Res. 2006; 23(12): 2709-28.

20. Nair $A B$, Jacob $S$. A simple practice guide for dose conversion between animals and human. J Basic Clin Pharm. 2016; 7(2): 27-31.

21. Nair A, Gupta R, Vasanti S. In vitro controlled release of alfuzosin hydrochloride using HPMC-based matrix tablets and its comparison with marketed product. Pharm Dev Technol. 2007; 12(6): 621-625.

22. Wadhwa J, Nair A, Kumria R. Emulsion forming drug delivery system for lipophilic drugs. Acta Pol Pharm Drug Res. 2012; 69(2): 179-191.

23. Karande $P$, Mitragotri $S$. Enhancement of transdermal drug delivery via synergistic action of chemicals. Biochim Biophys Acta. 2009; 1788(11): 236273.

24. Nair AB, Sammeta SM, Kim HD, Chakraborty B, Friden PM, Murthy SN. Alteration of the diffusional barrier property of the nail leads to greater terbinafine drug loading and permeation. Int J Pharm. 2009; 375(1-2): 22-7.

25. Anroop B, Ghosh B, Parcha V, Khanam J. Transdermal delivery of atenolol: effect of prodrugs and iontophoresis. Curr Drug Deliv. 2009; 6(3): 280-90.

26. Marwah H, Garg T, Goyal AK, Rath G. Permeation enhancer strategies in transdermal drug delivery. Drug Deliv. 2016; 23(2):564-78.

27. Lane ME. Skin penetration enhancers. Int J Pharm. 2013; 447(1-2): 12-21.

28. Nair AB, Chakraborty $B$, Murthy $S N$. Effect of polyethylene glycols on the trans-ungual delivery of terbinafine. Curr Drug Deliv. 2010; 7(5): 407-414.

29. Murthy SN, Vaka SR, Sammeta SM, Nair AB. TranScreen-N: Method for rapid screening of trans-ungual drug delivery enhancers. J Pharm Sci. 2009; 98(11): 4264-71.

30. Benet LZ, Broccatelli F, Oprea TI. BDDCS applied to over 900 drugs. AAPS J. 2011; 13(4): 519-47. 